\title{
(2) OPEN ACCESS \\ Injection laryngoplasty for laryngeal cleft type I in an 8-week-old infant
}

\author{
Marit J B van Stigt (10 , Hanneke D van Oorschot 주, Arnold J N Bittermann
}

Otorhinolaryngology and Head \& Neck Surgery, UMC Utrecht, Utrecht, Netherlands

\section{Correspondence to}

Marit J B van Stigt;

m.j.b.vanstigt-3@umcutrecht.nl

MJBvS and HDvO are joint first authors.

Accepted 31 January 2022

Check for updates

(c) BMJ Publishing Group Limited 2022. Re-use permitted under CC BY-NC. No commercial re-use. See rights and permissions. Published by BMJ.

To cite: van Stigt MJB, van Oorschot HD, Bittermann AJN. BMJ Case Rep 2022;15:e247014. doi:10.1136/bcr-2021247014

\section{SUMMARY}

A laryngeal cleft is a rare anatomical deformity which is increasingly treated with injection laryngoplasty. Since diagnosis of laryngeal cleft type I is often made between 2 and 5 years of age, this treatment is rarely performed on very young children. In this case, we describe how injection laryngoplasty is performed safely on an 8-weekold child, and we illustrate its added value for the diagnostic process and for temporary symptom relief.

\section{BACKGROUND}

A laryngeal cleft (LC) is an anatomical defect, consisting of a deeper notch in the interarytenoid region. ${ }^{1}$ This can result in overflow of food and liquids towards the trachea, and cause symptoms of aspiration, cough, recurring respiratory tract infections and respiratory distress. ${ }^{12}$ This can lead to diminished quality of life (QoL). ${ }^{3}$ A type I laryngeal cleft (T1LC) only extends to the supraglottic interarytenoid region, no further than the true vocal folds. ${ }^{3}$ A subclassification of T1LC is the deep interarytenoid notch (DIN). A DIN has normal musculature and a shorter interarytenoid notch height compared to a T1LC. ${ }^{4}$ Symptoms of T1LC are often non-specific. Because of this less distinct presentation of symptoms, diagnosis of T1LC is often delayed. According to previous research, type I and II LC are usually diagnosed between the age of 2 and 5 years. ${ }^{1}$ Gold standard for diagnosis is through palpation of the interarytenoid region using a probe, during suspension laryngoscopy under general anaesthetic. ${ }^{2}$ In approximately $58 \%-68 \%$ of patients with an LC, other congenital malformations are found. Associated anomalies are most commonly found in the gastrointestinal tract, including oesophageal atresia, tracheoesophageal fistula (TEF) and intestinal malrotation. ${ }^{15}$ Furthermore, an LC can lead to diminished QoL, by causing emotional and financial stress. ${ }^{6}$ Injection laryngoplasty (IL) using a dermal filler is increasingly used in the management of LC. ${ }^{2}$ This treatment is not often performed on newborn children, as in this case. Literature on the efficacy and safety of IL in younger children is therefore limited.

\section{CASE PRESENTATION}

A $31+5$ week premature boy, with a birth weight of $1275 \mathrm{~g}$, presented with respiratory distress and persistent continuous positive airway pressure (CPAP) dependency since birth. Nasogastric feeding tube insertion failed at $10 \mathrm{~cm}$. Further diagnostics indicated a type $\mathrm{C}$ oesophageal atresia with a TEF and a ventricular septal defect. At 5 days of age, thoracoscopic correction of the oesophageal atresia was performed. Per-operative laryngeal inspection revealed a possible mild T1LC, without signs of laryngomalacia. Postoperatively, oxygen dependency persisted, without the need for CPAP. Oral feeding was started under supervision of a speech and language therapist, and bottle feeding using only thickened liquids improved gradually. Additional portions could be administered through a nasoduodenal tube when the child (partially) refused bottle feeding. Nonetheless, incidents of aspiration occurred, and the child developed aspiration pneumonia. This clinical presentation and the possibility of an LC gave reason to perform a diagnostic laryngotracheobronchoscopy (dLTB).

\section{INVESTIGATIONS}

At 7 weeks of age, Videofluoroscopic Swallowing Study (VFSS) was carried out to assess the suspected LC. The patient was assessed as a level 2 on the Penetration Aspiration Scale. ${ }^{7}$ During swallowing of slightly thick liquid (International Dysphagia Diet Standardization Initiative (IDDSI) level 1), penetration was seen several times, but no aspiration. There was no penetration or aspiration seen while swallowing moderately thick liquids (IDDSI level 2). ${ }^{8}$

To evaluate possible TEF recurrence, the patient underwent a dLTB at 8 weeks of age. Due to respiratory distress during this investigation, the presence of a recurred TEF could not be assessed, but severe obstructing tracheobronchomalacia with $\mathrm{CO}_{2}$ accumulation was observed in addition to an oesophageal stenosis. Also, palpation of the interarytenoid area indicated either a T1LC or a DIN.

\section{DIFFERENTIAL DIAGNOSIS}

Since TEF recurrence could not be determined during dLTB, presenting symptoms could be attributed to either one or several of the following diagnoses; a fistula recurrence, the observed obstructing tracheobronchomalacia or an LC.

\section{TREATMENT}

Considering the symptoms of aspiration, the associated aspiration pneumonia, and the uncertainty which diagnosis was causative for presented symptoms, treating physicians decided to perform IL using a hyaluronic acid (HA) agent (figure 1). This is a way to evaluate if the LC is significant in causing the symptoms. The HA agent used in our institution is Juvéderm Ultra 3 (Allergan, France). During suspension laryngoscopy, the HA derivative is injected into the interarytenoid region. This 
A

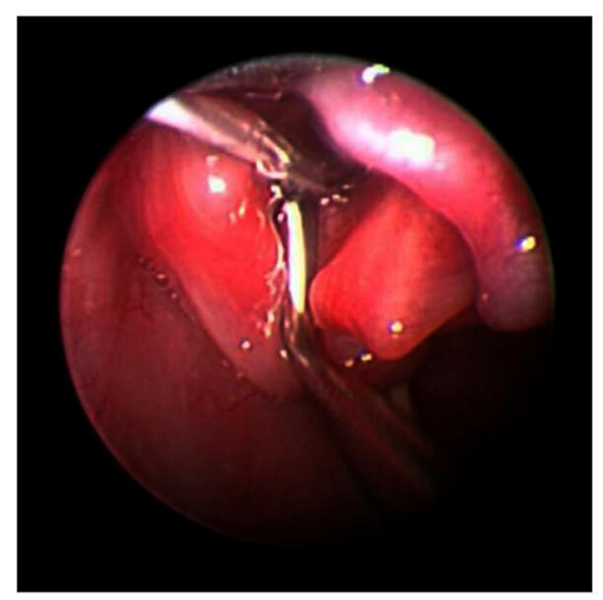

B

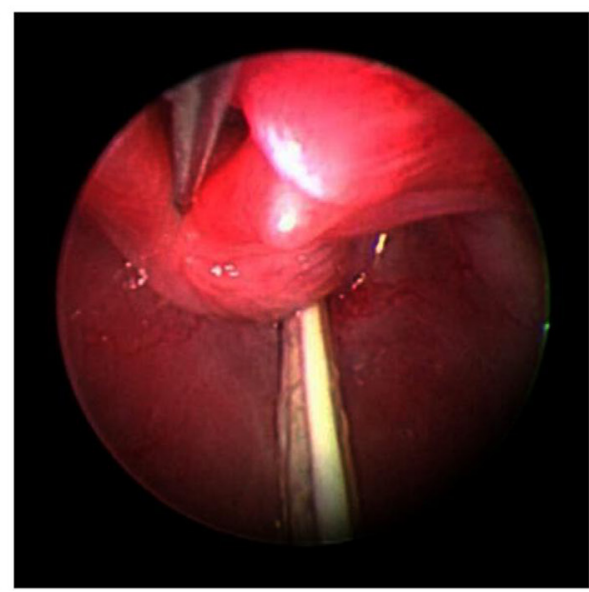

C

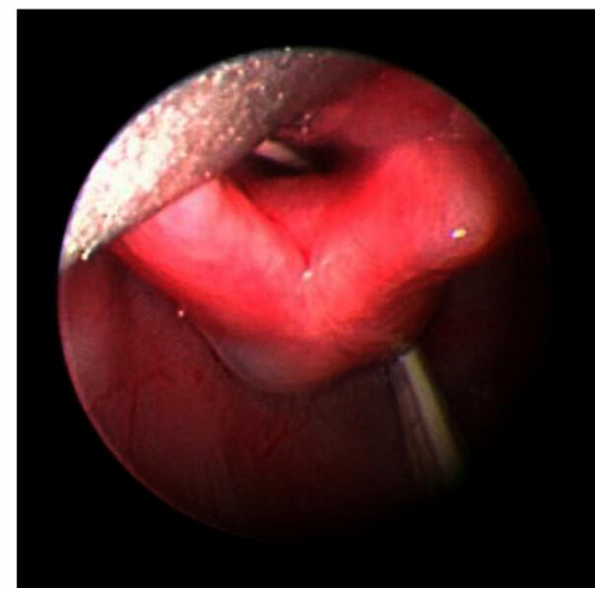

Figure 1 Interarytenoid injection laryngoplasty. Palpation of the laryngeal cleft using a probe (A), injection of hyaluronic acid filler (B), after injection laryngoplasty (C).

is done in order to add bulk and height to the interarytenoid region, and to thus decrease overflow of liquids towards the trachea. ${ }^{29}$ The injected volume of the HA agent is not measured. The treating physician injects an amount of filler that gives sufficient bulking, but causes no airway obstruction. Expected is that, as a result of less overflow into the trachea, symptoms of aspiration and symptoms caused by the aspiration, such as recurrent respiratory tract infections, will decrease. After some time, the HA derivative dissolves, and the deeper notch in the interarytenoid region reappears. If the LC was indeed causative, symptoms should subsequently return. ${ }^{2}$ Mean duration of symptom improvement after IL differs between previous studies, partly because of different agents injected. Cohen et al found that the mean duration of improvement of symptoms was 3.3 months. ${ }^{10}$ In another study using HA agent in IL for vocal cord medialisation, a median duration of 10.6 months was found. ${ }^{11}$

\section{OUTCOME AND FOLLOW-UP}

Initially, treating physicians saw an indication for posterior tracheopexy because of the oxygen dependency, $\mathrm{CO}_{2}$ accumulation and bronchial collapse. Per contra, the patient recovered postoperatively: oxygen therapy was unnecessary, $\mathrm{CO}_{2}$ levels decreased and there were no signs of respiratory distress. Oral feeding was resumed under logopedic supervision. Also, VFSS from before and after IL was compared, showing decreased aspiration at the level of the glottis. These findings suggested that the symptoms were caused predominantly by the LC.

However, 16 days later, the patient presented with an aspiration incident as a result of TEF recurrence, confirmed with a barium swallow study. This required revision surgery at 15 weeks, 48 days after the last dLTB, with tracheopexy and TEF resection. Per-operative laryngeal inspection showed a persistent, or possibly recurrence of, the T1LC, on which IL was revised. No postoperative complications occurred, leading to a quick recovery. After resumption of logopedic guided oral feeding, the patient could be discharged at 16 weeks of age.

\section{DISCUSSION}

IL is used to determine whether presenting symptoms can be attributed to this small anatomical defect. Therefore, it serves both as a diagnostic tool and a temporary treatment. In this case, there were two other possible causes for these symptoms, each with a different treatment approach. For an LC, standard treatment is surgical repair of the cleft by approximating cleft sides using sutures. ${ }^{12}$ According to Chew et al, complications occur in $10 \%-65 \%$ of paediatric airway procedures. ${ }^{12}$ The paediatric airway anatomically differs to that of adults, particularly in infants younger than 1 year old. Laryngoscopy is consequently more difficult in this age group and the view is suboptimal. ${ }^{13}$ Therefore, there should be a confident indication before surgical intervention, especially in a child of this age, which can be provided by IL.

Currently, IL is mostly performed on older children. The mean age at performance of IL was 11.8 months and 29 months in the research of Cohen et al and Ramazani et al respectively. ${ }^{9}{ }^{10}$ In this case, IL was performed on a child of 8 weeks old and again at 15 weeks. Known complications of IL include stridor, croup-like cough, and respiratory distress as a result of postoperative swelling. ${ }^{9}$ According to a previous study, there was no difference in efficacy and safety of IL in children between 0-3 months of age and older children. ${ }^{14}$ However, one can presume that a smaller airway lumen is more easily affected by little swelling, according to Poiseulle's law. ${ }^{13}$ Also, a smaller airway lumen can make the procedure more intricate. Volume of filler injected should be assessed by the treating physician during the procedure. This depends on the extent of the cleft, the lumen of the airway treated and the way the filler automatically distributes inside the cleft, which differs per procedure. The physician cannot control the distribution of the filler and it can also create bulking into the airway lumen, causing obstruction and thereby stridor. It is therefore important to be cautious and precise with the amount of filler injected.

In our experience, IL is not often performed in smaller children and literature concerning IL in those cases is sparse. In our case, IL was performed safely in an 8-week-old child, and revised at 15 weeks of age. Diagnosis and intervention at an earlier age is associated with better outcomes. ${ }^{14}$

In this case, the infant did receive a posterior tracheopexy eventually, yet there was a clear indication for IL during the dLTB. As in this patient, children with an LC are often known to have other congenital malformations or diseases. These cloud the diagnostic process, as symptoms could derive from more than one condition, but these comorbidities could also enhance risks associated with surgery and anaesthesia. IL can bridge a few 
months in which the child's anatomy can mature, which could possibly lead to both the resolving of symptoms attributed to a newborn's anatomy, and a more developed infant which can be easier to perform anaesthesia and operate on. This way, IL can prevent unnecessary operative procedures in infants when certain diagnoses are confirmed or disproved. Also, as in this case, IL can be revised multiple times in one child, to extend the period of HA effect if necessary.

\section{Learning points}

- Injection laryngoplasty is rarely performed in newborns, and literature regarding safety in these children is sparse. In some cases, however, it can be a good way to relieve symptoms and improve the overall health of a child.

- Injection laryngoplasty has a temporary effect. It can, however, be performed more than once.

- For children with comorbidities in need of surgery, in addition to a laryngeal cleft, injection laryngoplasty at a young age can provide a period of symptom improvement, to bridge the time that is needed for the child to get in better condition for surgery.

- Injection laryngoplasty can prevent unnecessary operative procedures in infants, by confirming or eliminating a laryngeal cleft as the cause of the symptoms.

Contributors All authors contributed significantly to this case report. Both HDvO and MJBvS contributed equally in data extraction and writing of the case report. They will both be guarantor. They therefore are joint first author. AJNB checked and edited the case report, provided guidance and communicated with the patient/parents.

Funding The authors have not declared a specific grant for this research from any funding agency in the public, commercial or not-for-profit sectors.

Competing interests None declared.

Patient consent for publication Consent obtained from parent(s)/guardian(s).

Provenance and peer review Not commissioned; externally peer reviewed.

Open access This is an open access article distributed in accordance with the Creative Commons Attribution Non Commercial (CC BY-NC 4.0) license, which permits others to distribute, remix, adapt, build upon this work non-commercially, and license their derivative works on different terms, provided the original work is properly cited and the use is non-commercial. See: http://creativecommons.org/ licenses/by-nc/4.0/.

Case reports provide a valuable learning resource for the scientific community and can indicate areas of interest for future research. They should not be used in isolation to guide treatment choices or public health policy.

\section{ORCID iDs}

Marit J B van Stigt http://orcid.org/0000-0002-2483-8719

Hanneke D van Oorschot http://orcid.org/0000-0001-6858-3984

\section{REFERENCES}

1 Johnston DR, Watters K, Ferrari LR, et al. Laryngeal cleft: evaluation and management. Int J Pediatr Otorhinolaryngol 2014;78:905-11.

2 Isaac A, El-Hakim H. Type 1 laryngeal cleft and feeding and swallowing difficulties in infants and toddlers: a review. Clin Otolaryngol 2019;44:107-13.

3 Benjamin B, Inglis A. Minor congenital laryngeal clefts: diagnosis and classification. Ann Otol Rhinol Laryngol 1989;98:417-20.

4 Basharat U, Schraff S, Stevens LM, et al. Deep interarytenoid Notch in young children managed with systematic thickener wean and injection laryngoplasty. Int J Pediatr Otorhinolaryngol 2019:118:115-9.

5 Landry AM, Rutter MJ. Airway anomalies. Clin Perinatol 2018;45:597-607.

6 Irace AL, Walker RD, Kawai K, et al. Development and validation of a quality of life instrument for patients with laryngeal cleft. Int J Pediatr Otorhinolaryngol 2018;108:143-50.

7 Rosenbek JC, Robbins JA, Roecker EB, et al. A penetration-aspiration scale. Dysphagia 1996:11:93-8.

8 International Dysphagia Diet Standardization Initiative. Complete IDDSI framework detailed definitions 2.0, 2019: 1-26.

9 Ramazani F, Isaac A, Johannsen W, et al. Side effects and complications of injection laryngoplasty for treatment of congenital type 1 laryngeal clefts. Int J Pediatr Otorhinolaryngol 2020;131:109886.

10 Cohen MS, Zhuang L, Simons JP, et al. Injection laryngoplasty for type 1 laryngeal cleft in children. Otolaryngol Head Neck Surg 2011;144:789-93.

11 Bertroche JT, Radder M, Kallogjeri D, et al. Patient-defined duration of benefit from juvederm (hyaluronic acid) used in injection laryngoplasty. Laryngoscope 2019;129:2744-7.

12 Chew L, Su-Velez BM, Miller JE, et al. 30-Day readmission rates, diagnoses, and risk factors following pediatric airway surgery. Int J Pediatr Otorhinolaryngol 2020;136:110141.

13 Harless J, Ramaiah R, Bhananker SM. Pediatric airway management. Int J Crit IIIn In Sci 2014:4:65-70.

14 Cole E, Dreyzin A, Shaffer AD, et al. Outcomes and swallowing evaluations after injection laryngoplasty for type I laryngeal cleft: does age matter? Int J Pediatr Otorhinolaryngol 2018;115:10-18.

Copyright 2022 BMJ Publishing Group. All rights reserved. For permission to reuse any of this content visit

https://www.bmj.com/company/products-services/rights-and-licensing/permissions/

BMJ Case Report Fellows may re-use this article for personal use and teaching without any further permission.

Become a Fellow of BMJ Case Reports today and you can:

- Submit as many cases as you like

- Enjoy fast sympathetic peer review and rapid publication of accepted articles

- Access all the published articles

Re-use any of the published material for personal use and teaching without further permission

Customer Service

If you have any further queries about your subscription, please contact our customer services team on +44 (0) 2071111105 or via email at support@bmj.com.

Visit casereports.bmj.com for more articles like this and to become a Fellow 